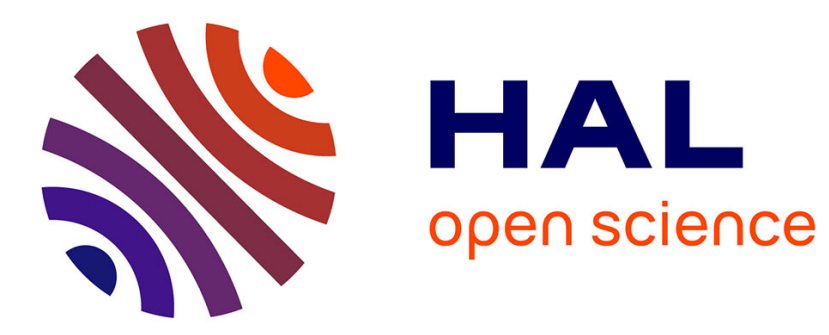

\title{
Fuzzy logic controllers for electrotechnical devices - On-site tuning approach
}

\author{
Daniel Hissel, Pascal Maussion, Jean Faucher
}

\section{To cite this version:}

Daniel Hissel, Pascal Maussion, Jean Faucher. Fuzzy logic controllers for electrotechnical devices On-site tuning approach. European Physical Journal: Applied Physics, 2001, 16 (3), pp.195-208. hal-00694054

\section{HAL Id: hal-00694054 https://hal.science/hal-00694054}

Submitted on 3 May 2012

HAL is a multi-disciplinary open access archive for the deposit and dissemination of scientific research documents, whether they are published or not. The documents may come from teaching and research institutions in France or abroad, or from public or private research centers.
L'archive ouverte pluridisciplinaire HAL, est destinée au dépôt et à la diffusion de documents scientifiques de niveau recherche, publiés ou non, émanant des établissements d'enseignement et de recherche français ou étrangers, des laboratoires publics ou privés. 


\title{
Fuzzy logic controllers for electrotechnical devices - On-site tuning approach
}

\author{
D. Hissel ${ }^{1,2}$, P. Maussion ${ }^{1}$, and J. Faucher ${ }^{1, a}$ \\ 1 Institut National Polytechnique de Toulouse, École Nationale Supérieure d'Électrotechnique, d'Électronique, d'Informatique \\ et d'Hydraulique de Toulouse, Laboratoire d'Électrotechnique et d'Électronique Industrielle ${ }^{\mathrm{b}}$, 2 rue Camichel, BP 7122 , \\ 31071 Toulouse Cedex 7, France \\ 2 Institut National Polytechnique de Toulouse, École Nationale Supérieure d'Électrotechnique, d'Électronique, d'Informatique \\ et d'Hydraulique de Toulouse, Laboratoire d'Électronique, Électrotechnique et Systèmes, LRE-T31 INRETS-UTBM-UFC, \\ Parc Technologique, 90000 Belfort, France
}

Received: 13 March 2000 / Revised: 8 March 2001 / Accepted: 20 July 2001

\begin{abstract}
Fuzzy logic offers nowadays an interesting alternative to the designers of non linear control laws for electrical or electromechanical systems. However, due to the huge number of tuning parameters, this kind of control is only used in a few industrial applications. This paper proposes a new, very simple, onsite tuning strategy for a PID-like fuzzy logic controller. Thanks to the experimental designs methodology, we will propose sets of optimized pre-established settings for this kind of fuzzy controllers. The proposed parameters are only depending on one on-site open-loop identification test. In this way, this on-site tuning methodology has to be compared to the Ziegler-Nichols one's for conventional controllers. Experimental results (on a permanent magnets synchronous motor and on a DC/DC converter) will underline all the efficiency of this tuning methodology. Finally, the field of validity of the proposed pre-established settings will be given.
\end{abstract}

PACS. 84.60.Bk Performance characteristics of energy conversion systems; figure of merit 07.05.Fb Design of experiments - 07.05.Mh Neural networks, fuzzy logic, artificial intelligence

\section{Introduction}

Among the various types of control laws, the designers can nowadays have recourse to fuzzy logic. This type of control, in addition to its intrinsically nonlinear aspect and to the good dynamic performances allowed, gives the designer the possibility of incorporating the human operators experiment for the process control in his command law. As we will see it thereafter, the main handicap of this type of control is the huge number of parameters that have to be tuned. Moreover, the adjustment of these parameters is often unclear, the designer is generally satisfied to fix some of them at an average value while the others are fixed thanks to a fine knowledge of the process to control. Unfortunately, it does not exist today a general, systematic, simple and robust method for the adjustment of fuzzy controllers. This difficulty for their implementation is often a barrier to a more widespread use in spite of the resulting dynamic performances improvement compared to conventional control methods. The aim and the main contribution is neither here to compare various types of controls, nor their methods of parameters calculation, but to

\footnotetext{
a e-mail: faucher@leei.enseeiht.fr

b UMR CNRS n ${ }^{\circ} 5828$
}

provide simple tools for the fast and experimental on-site tuning of a fuzzy PID-type controller, from preestablished adjustments, after only one open-loop step input.

In this paper, we will thus study fuzzy PID control structures of which we will systematize the parameters adjustment with the help of the experimental designs $[3,8,10,11]$. This powerful methodology finds here a great field of application for non-linear control laws optimization. The parameters tuning will optimize, on a given benchmark and in terms of performances and robustness, the response of an open-loop system modeled by a first order plus dead time or of an open-loop evolutive system.

In this way, this adjustment procedure approaches, on the methodology, the experimental adjustments provided by Broida or Ziegler-Nichols [12] for conventional PID controllers. Nevertheless, the optimization criterion is not here the damping ratio or the gain margin but the IAE criterion (integrative absolute error). The minimization of such a criterion makes it possible to optimize the system response during both no-load step response and load regulation, and even with non linearities such as saturations.

In a first part of this paper, the considered fuzzy controller will be described. Then a first set of preestablished settings, that can only be used in non-noisy environments, will be provided. A second set of preestablished settings 


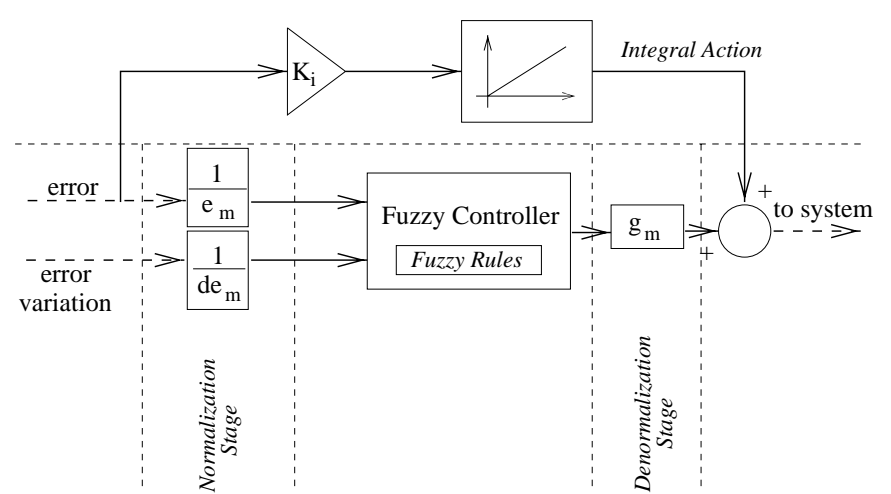

Fig. 1. PID-like fuzzy controller.

for the same PID-like fuzzy controller, that takes into account the possibility of the presence of white noise, a process misidentification of an high order process, will be given in a third part of this paper. Finally, a last set of settings, that added to the second set the controller robustness versus solicitation magnitude will be provided. As the field of validity of a tuning methodology should always be associated to its statement, a last part of this paper is devoted to the limitations of our proposed preestablished settings. All the proposed settings were validated on two types of experimental systems: a DC/DC buck converter and a permanent magnet synchronous machine.

\section{System presentation}

First of all, the FLC that will be used in the whole paper has to be presented. This controller is a classical PIDlike fuzzy controller (see Fig. 1). A two-inputs/one-output Sugeno type FLC [9] with seven triangular membership functions is used [2]. In addition, a crisp integrator is placed parallel of this controller so as to ensure a zero steady-state error. The considered rules base is a classical antidiagonal one's. Of course, due to the fact that seven membership functions are chosen on both inputs and that only seven output singletons are considered, two saturation areas appear on the boundaries of this rules base. The parameters of such a controller are very numerous: for the fuzzy part, the 3 normalization and denormalization gains, the 49 fuzzy rules, the 7 positions of the membership functions at the two inputs, the 7 positions of the singletons at the output; for the crisp part, the value of the integrator gain, so, at least, 74 parameters to tune.

The determination of optimum values for all this parameters according to a specified benchmark (in our case: no-load step start, nominal load regulation, no-load regulation) and criterion (in our case the integral of absolute error (IAE) between the reference and the measured signal) is far from easy $[4,7]$. In this paper, the criterion optimization is obtained by modifying the level of nine "major" factors, which contribution to the result seams to be the highests. These nine factors are the six membership positions factors defined in Figures $2 \mathrm{a}$ and $2 \mathrm{~b}$ (and called $A, B$ on input $e, C, D$ on input de and $E, F$ at the output), the integrator gain $K_{\mathrm{i}}$ (called $G$ ), the error derivative normalization factor $d_{\mathrm{em}}$ (called $H$ ) and the denormalization gain $g_{\mathrm{m}}$ (called $I$ ). On each input of the FLC, the positions of the PS's and PVS's membership function's apex are mobile. A zero-symmetry and a 50\%overlapping rate are always maintained and the PB's and NB's membership functions apex are fixed (at +1 and -1 respectively). At the output of the fuzzy controller, as we use a Sugeno-style fuzzy logic controller, the output membership functions are singletons. As on the inputs, the positions of the PS's and PVS's singletons are mobile and a zero-symmetry is maintained.

In this paper, pre-established values for these nine parameters will be provided, but only three of this parameters (two of the normalization gains and the integrator gain) will depend on the open-loop identification of the process. The others will be defined on the normalized universe of discourse. In this way, this methodology can be seen as a Ziegler-Nichols-like tuning strategy [12] for fuzzy controllers. For open-loop stable processes, the open-loop step response of the process will provide three parameters $K, T$ and $\tau$ for an open-loop transfer function of the process that can be expressed as equation (1) (Fig. 3a). For evolutive open-loop processes, the open-loop step response of the process will provide two parameters $K$ and $T$ for an open-loop transfer function of the process that can be expressed as equation (2) (Fig. 3b).

$$
T F(p)=K \frac{\mathrm{e}^{-T p}}{1+\tau p} \text { with }\left\{\begin{array}{l}
T: \text { dead time } \\
\tau: \text { time constant } \\
K: \text { open-loop gain }
\end{array}\right.
$$

$$
T F(p)=K \frac{\mathrm{e}^{-T p}}{p} \text { with }\left\{\begin{array}{l}
T: \text { dead time } \\
K: \text { open-loop gain. }
\end{array}\right.
$$

\section{Standard settings for a PID-like FLC}

\subsection{Experimental designs methodology}

Considering for example only two levels for each of the nine factors described above, the classical experimental tuning method that consists in varying one of the parameters when all the others are maintained constant, results in $2^{9}=512$ required experiments in order to test all cases and to find the suitable combination of factors levels that minimize the $I A E$-criterion. The main difference between this classical experimental method and the experimental designs method resides in the fact that the level of each factor is modified at each experiment according to a specific procedure $[3,4]$. This allows a drastic reduction of the number of required experiments, the possibility of taking into account much more parameters, the detection of interactions between factors and a result optimization.

To simplify the experimental strategy definition, predefined tables have been published [8] based on the hypothesis that second-order interactions (that are interactions between three factors) are always negligible. These tables are called "experiment matrices" and are noted 

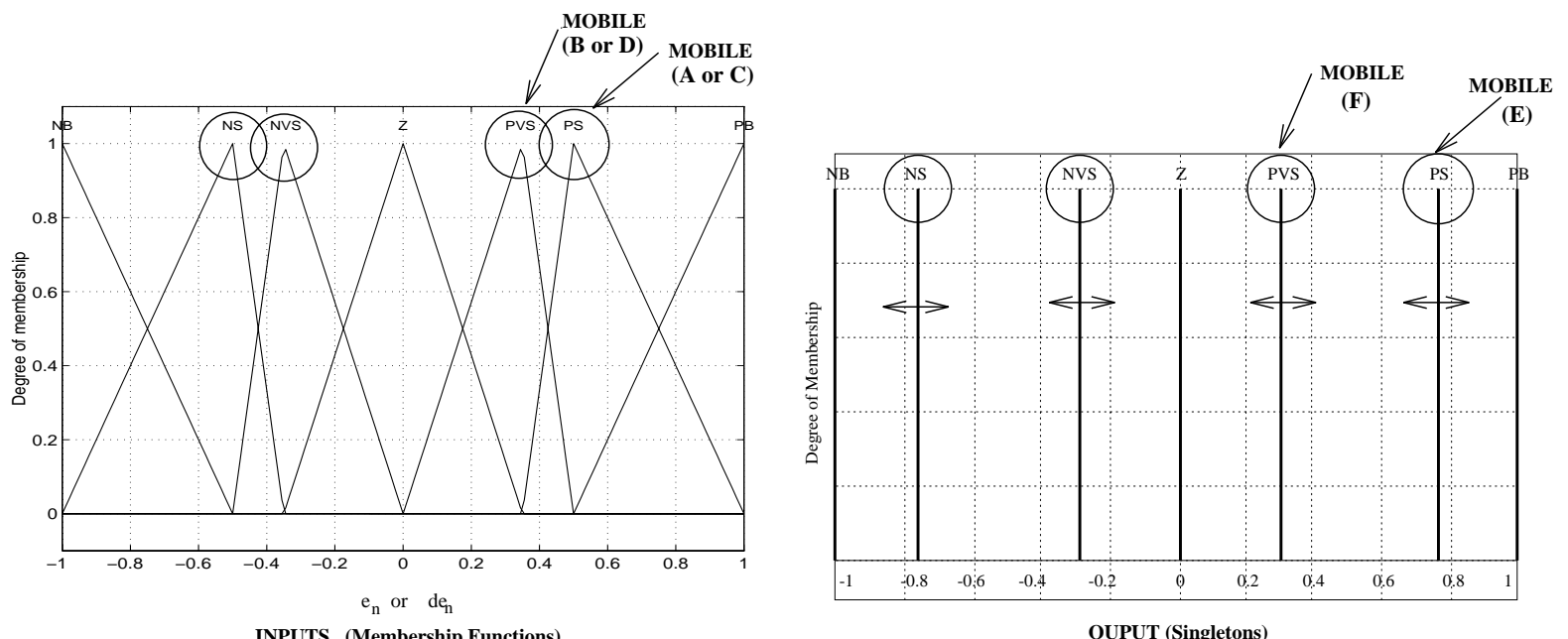

Fig. 2. Factors definition.

a. Open-loop stable process

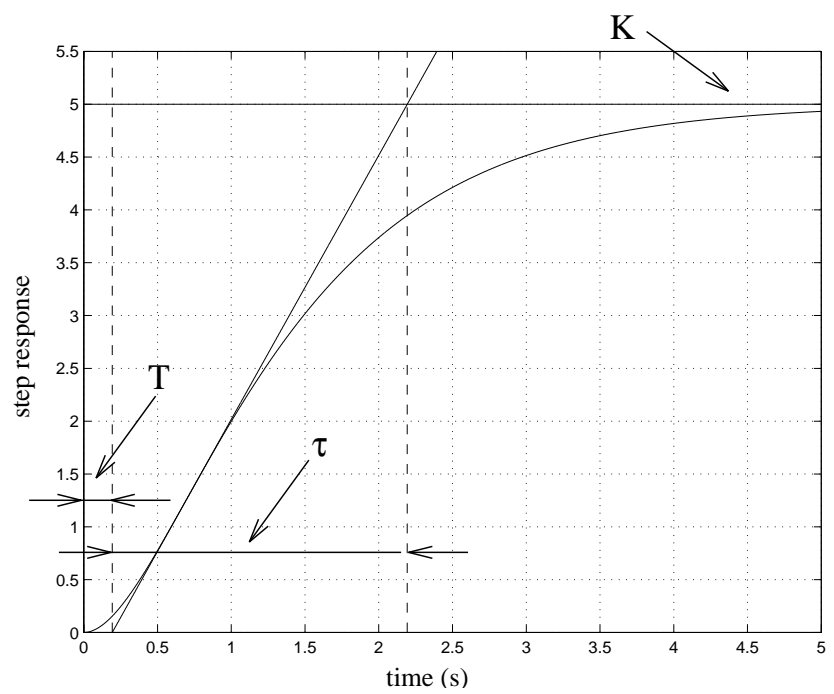

b. Open-loop evolutive process

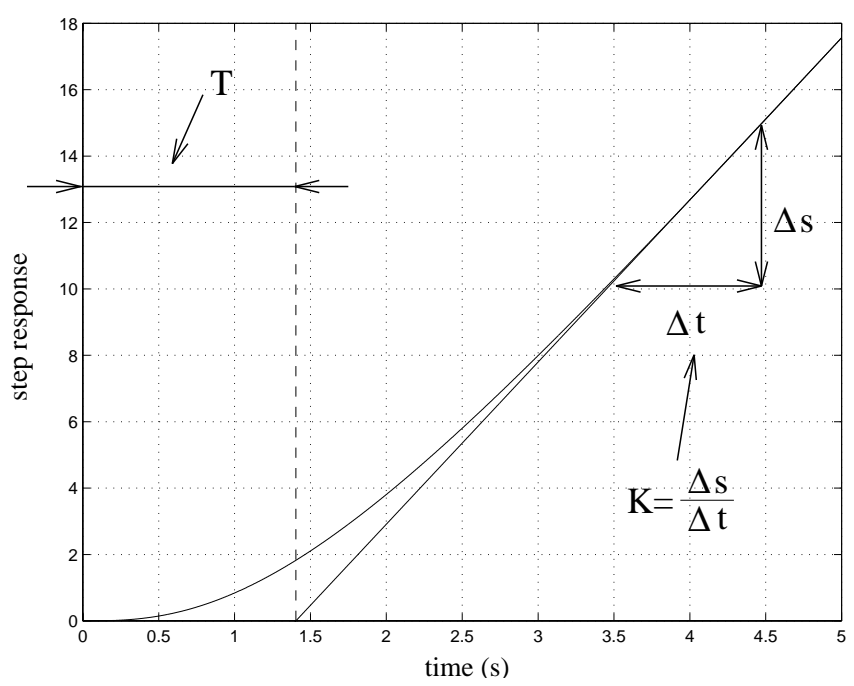

Fig. 3. Step response of the open-loop process.

$\mathrm{L}_{a}\left(b^{c}\right)$ where $a$ is the number of required experiments, $b$ the number of levels for each factor and $c$ the number of factors that can be studied. Each row of such a table is assigned to one experiment and each column can be assigned to one factor. The first order interactions (if they exist...) are placed in the columns depending on the positions of the factors which are involved in these interactions. Numbers 1 and 2 symbolizes the (two) levels of each factor. When the required experiments have been done, the effect of each factor (noted $E_{A_{i}}$ ) added up by the effect of the first order interactions that are in the same column as the factor (noted $\Sigma E_{X Y}$ ) at a specified level $i$ can be determined according to the relation:

$$
E_{A_{i}}+\Sigma E_{X Y}=(\overline{I A E})_{A=i}-\overline{I A E} .
$$

If we suppose (or of course, if we know) that $\Sigma E_{X Y}$ cannot be neglected in front of $E_{A_{i}}$, it's possible to use a so-called complementary-table so as to evaluate $E_{A_{i}}-$ $\Sigma E_{X Y}$. Using these two equations, $E_{A_{i}}$ and $\Sigma E_{X Y}$ can then be evaluated separately. From this time onwards, it's easy to determine the combination of the factors levels which minimize the $I A E$-criterion.

\subsection{Application on the PID-like FLC}

In our case, only two discrete levels are chosen for each of the nine factors in order to reduce the number of required experiments. These two levels are defined in a relative way for factors $A$ to $D$ due to the mechanical constraint which exists between the positions of membership functions apex. To illustrate this fact, let us consider the value 0.7 for factor $A$; in that case, the position of factor $B$ must be between 0 and 0.7 . Thus, considering the 
Table 1. Levels 1 and 2 for the chosen factors.

\begin{tabular}{ccc}
\hline Factors & Level 1 & Level 2 \\
\hline A & 0.3 & 0.7 \\
B & 0.3 & 0.7 \\
C & 0.3 & 0.7 \\
D & 0.3 & 0.7 \\
E & 0.8 & 0.4 \\
F & 0.6 & 0,2 \\
G & $\frac{0.5}{K T}$ & $\frac{1.5}{K T}$ \\
& $1 \frac{(\tau+0.4 T) T_{\text {samp }}}{\tau T}$ & $3 \frac{(\tau+0.4 T) T_{\text {samp }}}{\tau T}$ \\
H & $0.5 \frac{(\tau+0.4 T)}{K T}$ & $1.5 \frac{(\tau+0.4 T)}{K T}$ \\
I & &
\end{tabular}

relative value 0.7 ( $70 \%$ of the remaining interval) for $B$ corresponds in fact, to the absolute position 0.49. The two chosen levels are provided in Table 1 (for the open-loop stable case).

The choice of the two levels for factors $G, H$ and $I$ has been done by taking one's inspiration from the Broïda predefined settings for conventional PID controllers [1]. For example in case of an open-loop stable process, Broïda proposes the settings provided in equation (4) for $K_{\mathrm{p}}, K_{\mathrm{i}}$ and $K_{\mathrm{d}}$.

$$
\begin{cases}K_{\mathrm{p}}: & \frac{(0.8)}{K T}(\tau+0.4 T) \\ K_{\mathrm{i}}: & \frac{0.8}{K T} \\ K_{\mathrm{d}}: & \frac{0.32 \tau}{K} .\end{cases}
$$

Intuitively, under the assumptions of an equal-interval scaling of membership functions and of a non-saturation of the control values, relationships such as $K_{\mathrm{p}}=g_{\mathrm{m}} / e_{\mathrm{m}}$ and $K_{\mathrm{d}}=g_{\mathrm{m}} / d e_{\mathrm{m}}$ can be shown. Thus, two levels have been chosen in terms of $K, T$ and $\tau$ on both sides of the Broïda settings obtained for $d e_{\mathrm{m}}, g_{\mathrm{m}}$ and $K_{\mathrm{i}}$ (considering a normalized solicitation $e_{\mathrm{m}}=1$ ).

It has here been possible to obtain the optimized combination of factors levels according to the $I A E$-criterion in only 32 experiments instead of 512 . Table 2 provides the simulation results in case of an open-loop stable process $(K=5, T=0.192 \mathrm{~s}, \tau=2 \mathrm{~s})$.

From this table and thanks to the so-called complementary-table, it becomes possible to separate the effects of each factor from the first-order interactions effects. Table 3 summarizes the calculation of the effects, assuming that second order interactions are negligible and according to a experimental design rule called inheritance interactions (the highest level for each factor, the highest interaction). Thus, it is possible to underline, in the first-order interactions summations, the most influential interactions. Considering these interactions effects and the nine factors effects, it is possible to determine the combination of factors levels that optimize the $I A E$-criterion: $A_{2} B_{2} C_{1} D_{2} E_{1} F_{1} G_{2} H_{1} I_{2}$. This combination leads to $I A E=0.395$ (this criterion is here supposed to be adimensional).

Until now, the definition of pre-established settings for the PID-like FLC has just been led on discrete levels. To ensure a fine optimization of these settings in the vicinity of those obtained in the last paragraph, a simplex algorithm has been used. The main handicap of this optimization algorithm resides in its high number of required experiments. Therefore and in order to reduce this number, the simplex has been led only on the most influential factors. Those can be identified thanks to the effects provided in Table 3.

Exactly the same procedure was followed in case of evolutive systems.

\subsection{Pre-established standard settings}

After a fine optimization of the most influent factors levels using a simplex algorithm, the final optimized settings for the FLC parameters in case of use with open-loop stable process are those given by equation (5). It can be noticed that the normalization factor on input $e$ (called $e_{\mathrm{m}}$ ) is here supposed to be defined considering the solicitation magnitude $s_{\mathrm{m}}$.

$$
\begin{cases}P S_{e} & : 0.25 \\ P V S_{e} & : 0.03 \\ P S_{d e} & : 0.70 \\ P V S_{d e} & : 0.21 \\ P S_{s} & : 0.80 \\ P V S_{s} & : 0.62 \\ e_{\mathrm{m}} & : s_{\mathrm{m}} \\ d e_{\mathrm{m}} & : \frac{(\tau+0.4 T) T_{\mathrm{samp}} s_{\mathrm{m}}}{\tau T} \\ g_{\mathrm{m}} & : \frac{2.07(\tau+0.4 T) s_{\mathrm{m}}}{K T} \\ K_{\mathrm{i}} & : \frac{1.60}{K T} .\end{cases}
$$

For open-loop evolutive systems, the optimized preestablished settings are (Eq. (6)):

$$
\begin{cases}P S_{e} & : 0.26 \\ P V S_{e} & : 0.02 \\ P S_{d e} & : 0.70 \\ P V S_{d e} & : 0.21 \\ P S_{s} & : 0.80 \\ P V S_{s} & : 0.70 \\ K_{\mathrm{i}} & : \frac{0.40}{K T^{2}} \\ e_{\mathrm{m}} & : s_{\mathrm{m}} \\ d e_{\mathrm{m}} & : 1.50\left(\frac{T_{\mathrm{samp}} s_{\mathrm{m}}}{T}\right) \\ g_{\mathrm{m}} & : \frac{2.25 s_{\mathrm{m}}}{K T} .\end{cases}
$$


Table 2. Table $\mathrm{L}_{16}\left(2^{15}\right)$ and complementary- $\mathrm{L}_{16}\left(2^{15}\right)$ table.

\begin{tabular}{ccccccccccc}
\hline Exp & A & B & C & D & E & F & G & H & I & IAE \\
\hline 1 & 1 & 1 & 1 & 1 & 1 & 1 & 1 & 1 & 1 & $\mathbf{1 . 7 9 2}$ \\
\hline 2 & 1 & 1 & 2 & 2 & 1 & 1 & 2 & 2 & 2 & $\mathbf{0 . 8 6 8}$ \\
\hline 3 & 1 & 1 & 1 & 1 & 2 & 2 & 2 & 1 & 2 & $\mathbf{1 . 0 1 8}$ \\
\hline 4 & 1 & 1 & 2 & 2 & 2 & 2 & 1 & 2 & 1 & $\mathbf{2 . 6 0 2}$ \\
\hline 5 & 1 & 2 & 1 & 1 & 2 & 1 & 1 & 2 & 2 & $\mathbf{0 . 7 0 2}$ \\
\hline 6 & 1 & 2 & 2 & 2 & 2 & 1 & 2 & 1 & 1 & $\mathbf{1 . 3 8 4}$ \\
\hline 7 & 1 & 2 & 1 & 1 & 1 & 2 & 2 & 2 & 1 & $\mathbf{1 . 7 1 8}$ \\
\hline 8 & 1 & 2 & 2 & 2 & 1 & 2 & 1 & 1 & 2 & $\mathbf{1 . 3 3 6}$ \\
\hline 9 & 2 & 1 & 1 & 2 & 2 & 1 & 1 & 1 & 2 & $\mathbf{0 . 6 3 0}$ \\
\hline 10 & 2 & 1 & 2 & 1 & 2 & 1 & 2 & 2 & 1 & $\mathbf{1 . 1 8 3}$ \\
\hline 11 & 2 & 1 & 1 & 2 & 1 & 2 & 2 & 1 & 1 & $\mathbf{1 . 1 7 4}$ \\
\hline 12 & 2 & 1 & 2 & 1 & 1 & 2 & 1 & 2 & 2 & $\mathbf{1 . 2 4 9}$ \\
\hline 13 & 2 & 2 & 1 & 2 & 1 & 1 & 1 & 2 & 1 & $\mathbf{0 . 9 4 2}$ \\
\hline 14 & 2 & 2 & 2 & 1 & 1 & 1 & 2 & 1 & 2 & $\mathbf{0 . 4 4 7}$ \\
\hline 15 & 2 & 2 & 1 & 2 & 2 & 2 & 2 & 2 & 2 & $\mathbf{0 . 7 0 8}$ \\
\hline 16 & 2 & 2 & 2 & 1 & 2 & 2 & 1 & 1 & 1 & $\mathbf{1 . 6 1 7}$ \\
\hline
\end{tabular}

Table 3. Calculation of effects.

\begin{tabular}{|c|c|c|c|c|c|}
\hline$E_{A_{1}}$ & $=$ & +0.222 & $\underline{E_{A B}}+E_{D H}$ & $=$ & +0.033 \\
\hline$E_{B_{1}}$ & $=$ & +0.176 & $E_{B E}+\underline{E_{H I}}$ & $=$ & +0.047 \\
\hline$E_{C_{1}}$ & $=$ & -0.059 & $E_{A E}+\underline{\underline{E_{D I}}}$ & $=$ & +0.066 \\
\hline$E_{D_{1}}$ & $=$ & +0.027 & $\underline{E_{F I}}+E_{E G}$ & $=$ & -0.047 \\
\hline$E_{E_{1}}$ & $=$ & -0.004 & $\underline{E_{A G}}+E_{D F}$ & $=$ & +0.020 \\
\hline$E_{F_{1}}$ & $=$ & -0.251 & $\underline{E_{B G}}+E_{F H}$ & $=$ & +0.035 \\
\hline$E_{G_{1}}$ & $=$ & +0.118 & $E_{E F}+\underline{E_{G I}}$ & $=$ & +0.006 \\
\hline$E_{H_{1}}$ & $=$ & +0.033 & $\underline{E_{A F}}+E_{D G}$ & $=$ & -0.072 \\
\hline \multirow[t]{4}{*}{$E_{I_{1}}$} & $=$ & +0.357 & $\underline{E_{B F}}+E_{G H}$ & $=$ & -0.045 \\
\hline & & & $\underline{E_{A H}}+E_{B D}$ & $=$ & +0.038 \\
\hline & & & $\underline{E_{B I}}+E_{E H}$ & $=$ & +0.012 \\
\hline & & & $\underline{E_{A I}}+E_{D E}$ & $=$ & +0.071 \\
\hline$E_{C D}$ & $=$ & -0.005 & $E_{C H}$ & $=$ & -0.072 \\
\hline$E_{A C}$ & $=$ & -0.022 & $E_{C I}$ & $=$ & -0.016 \\
\hline$E_{C G}$ & $=$ & +0.034 & $E_{C F}$ & $=$ & +0.030 \\
\hline$E_{B C}$ & $=$ & -0.069 & $E_{C E}$ & $=$ & -0.016 \\
\hline \multicolumn{4}{|c|}{$E_{A D}+\underline{E_{F G}}+E_{E I}+E_{B H}=$} & \multicolumn{2}{|c|}{-0.066} \\
\hline
\end{tabular}

\subsection{Experimental results}

\subsubsection{Open-loop stable systems}

In this case, the pre-established settings have been tested on both a DC/DC buck converter (output voltage control - supply voltage $=200 \mathrm{~V}$, IGBT power switches) and a PMSM (speed control, nominal torque $=5 \mathrm{Nm}$, maximal speed $=4500 \mathrm{rpm}$, type Mavilor BLS112) [6]. As the proposed standard settings have been obtained without taking into account the effect of white noise, a low-pass filter $(50 \mathrm{~Hz}$ for the converter and $10 \mathrm{~Hz}$ for the PMSM) has to be added. Thus, the open-loop identification tests

\begin{tabular}{ccccccccccc}
\hline Exp & A & B & C & D & E & F & G & H & I & IAE \\
\hline 1 & 1 & 1 & 1 & 2 & 1 & 2 & 1 & 2 & 2 & $\mathbf{1 . 7 8 2}$ \\
\hline 2 & 1 & 1 & 2 & 1 & 1 & 2 & 2 & 1 & 1 & $\mathbf{2 . 8 6 4}$ \\
\hline 3 & 1 & 1 & 1 & 2 & 2 & 1 & 2 & 2 & 1 & $\mathbf{1 . 3 5 4}$ \\
\hline 4 & 1 & 1 & 2 & 1 & 2 & 1 & 1 & 1 & 2 & $\mathbf{1 . 1 8 2}$ \\
\hline 5 & 1 & 2 & 1 & 2 & 2 & 2 & 1 & 1 & 1 & $\mathbf{2 . 1 7 7}$ \\
\hline 6 & 1 & 2 & 2 & 1 & 2 & 2 & 2 & 2 & 2 & $\mathbf{0 . 8 7 1}$ \\
\hline 7 & 1 & 2 & 1 & 2 & 1 & 1 & 2 & 1 & 2 & $\mathbf{0 . 6 0 6}$ \\
\hline 8 & 1 & 2 & 2 & 1 & 1 & 1 & 1 & 2 & 1 & $\mathbf{1 . 3 1 8}$ \\
\hline 9 & 2 & 1 & 1 & 1 & 2 & 2 & 1 & 2 & 1 & $\mathbf{2 . 0 0 8}$ \\
\hline 10 & 2 & 1 & 2 & 2 & 2 & 2 & 2 & 1 & 2 & $\mathbf{1 . 0 9 2}$ \\
\hline 11 & 2 & 1 & 1 & 1 & 1 & 1 & 2 & 2 & 2 & $\mathbf{0 . 6 3 3}$ \\
\hline 12 & 2 & 1 & 2 & 2 & 1 & 1 & 1 & 1 & 1 & $\mathbf{1 . 3 9 6}$ \\
\hline 13 & 2 & 2 & 1 & 1 & 1 & 2 & 1 & 1 & 2 & $\mathbf{0 . 7 2 3}$ \\
\hline 14 & 2 & 2 & 2 & 2 & 1 & 2 & 2 & 2 & 1 & $\mathbf{1 . 0 9 4}$ \\
\hline 15 & 2 & 2 & 1 & 1 & 2 & 1 & 2 & 1 & 1 & $\mathbf{1 . 1 1 0}$ \\
\hline 16 & 2 & 2 & 2 & 2 & 2 & 1 & 1 & 2 & 2 & $\mathbf{0 . 4 4 4}$ \\
\hline
\end{tabular}

are leading respectively to transfer functions (7) and (8).

$$
\begin{aligned}
& F T_{\mathrm{BC}}(p)=14.7 \frac{\mathrm{e}^{-0.0028 p}}{1+0.0174 p} \\
& F T_{\mathrm{SM}}(p)=-1580 \frac{\mathrm{e}^{-0.019 p}}{1+0.372 p} .
\end{aligned}
$$

Figures $4 \mathrm{a}$ and $4 \mathrm{~b}$ give the experimental results for the DC/DC converter controlled either by our PID-like FLC or by a conventional Broïda PID controller. The experimental results for the PMSM speed control are also provided in the two same cases (Figs. 5a and 5b).

With the optimized FLC, all the experiments lead to an outstanding improvement of the behavior with respect to the standard tunings of the Broïda PID controller (between $70 \%$ and $80 \%$ improvement of the $I A E$-criterion, overshoot and time response reduction).

\subsubsection{Open-loop evolutive systems}

The position control of the PMSM is an example of evolutive systems and its experimental step identification leads to the model given by transfer function (9).

$$
F T_{\text {pos }}(p)=-366 \frac{\mathrm{e}^{-0.032 p}}{p} .
$$

From this result, the settings of the PID-like FLC could be deducted from (6). Figures $6 \mathrm{a}$ and $6 \mathrm{~b}$ present only the experimental results for a step input and not for the whole considerated benchmark, because of our test possibilities. As for Broïda or Ziegler-Nichols controllers, i.e. from only one open-loop identification test, the FLC optimized through our procedure gives a very fast response with a slight overshoot.

\section{Robust settings for a PID-like FLC}

In the previous part, after having briefly described the experimental designs methodology, we applied it to obtain 
a. PID-like FLC

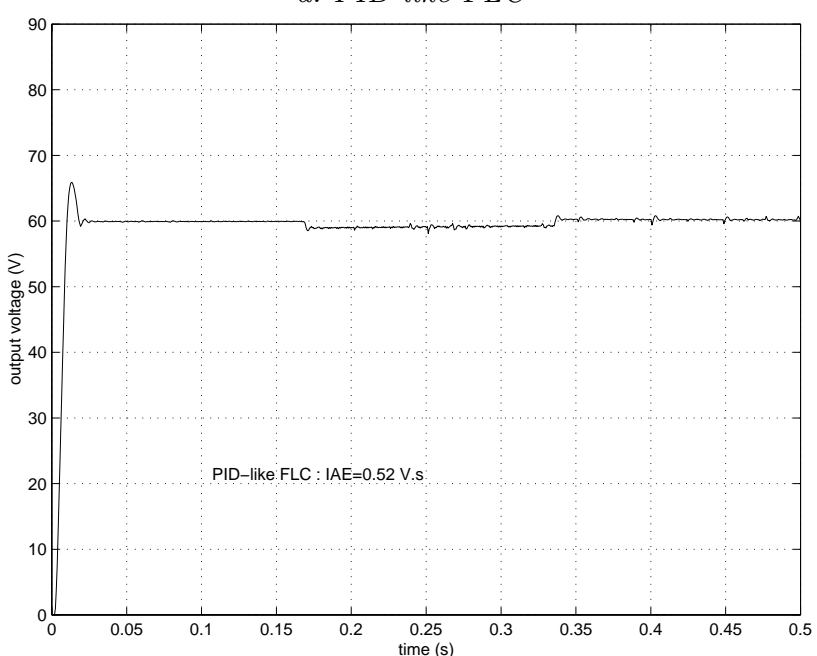

b. Broïda PID controller

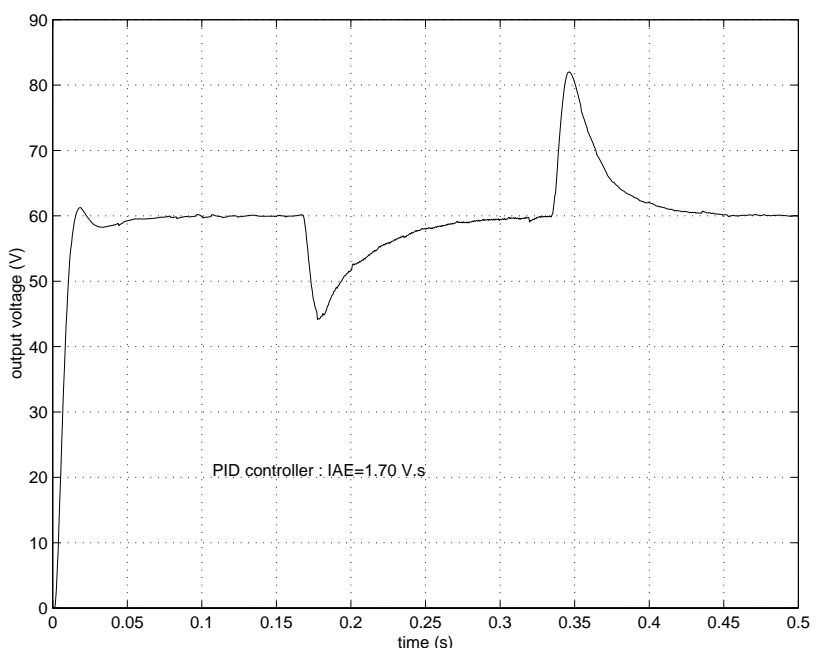

Fig. 4. Experimental results for the output voltage control of a DC/DC converter.

a. PID-like FLC

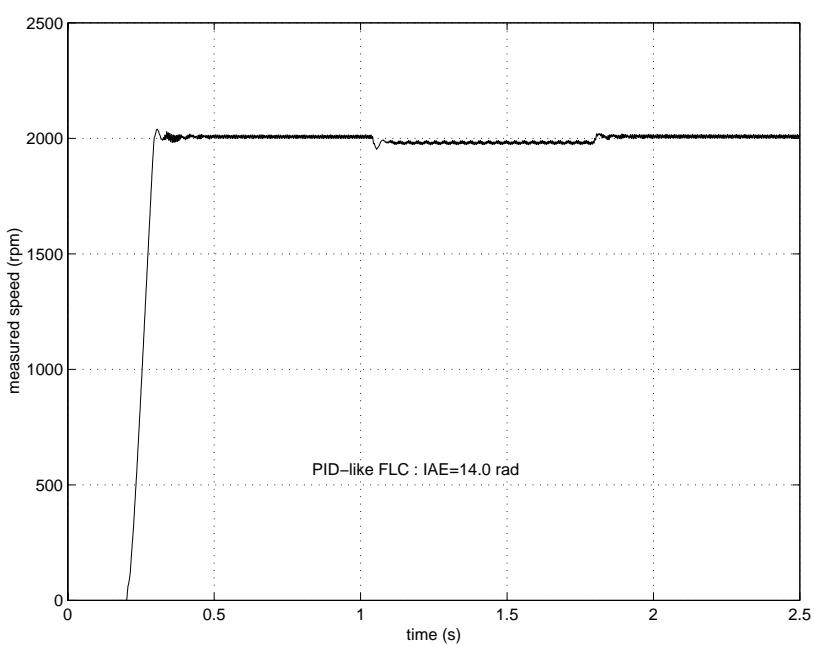

b. Brö̈da PID controller

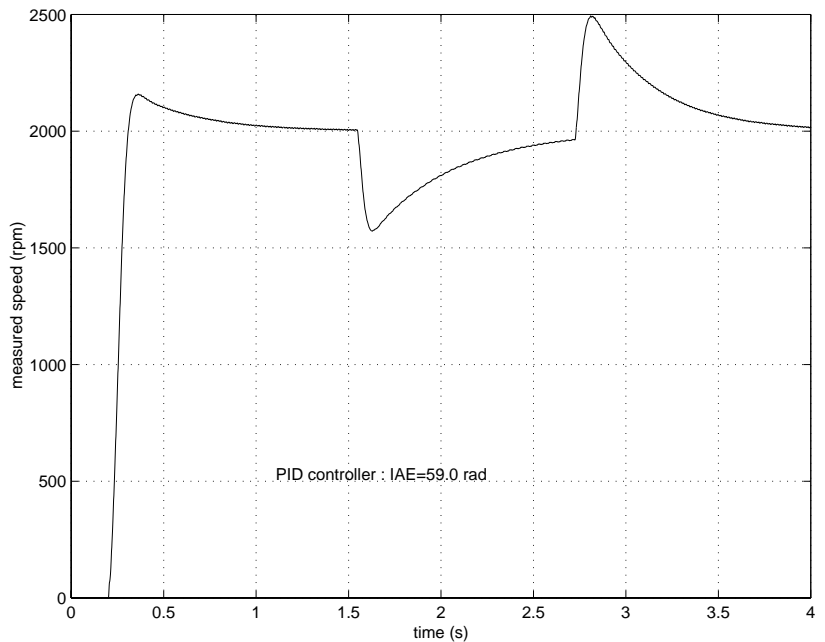

Fig. 5. Experimental results for the speed control of a PMSM.

a. PID-like FLC

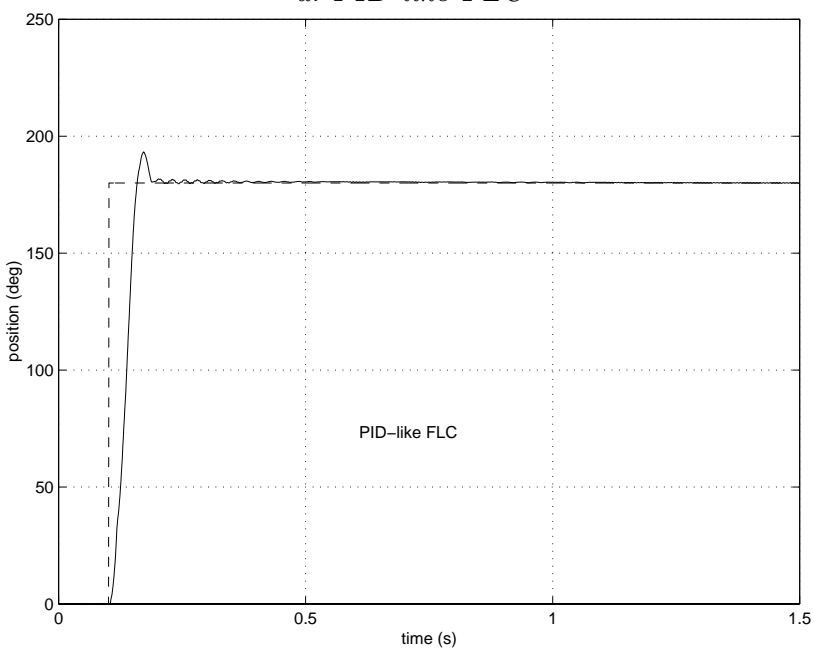

b. Broïda PID controller

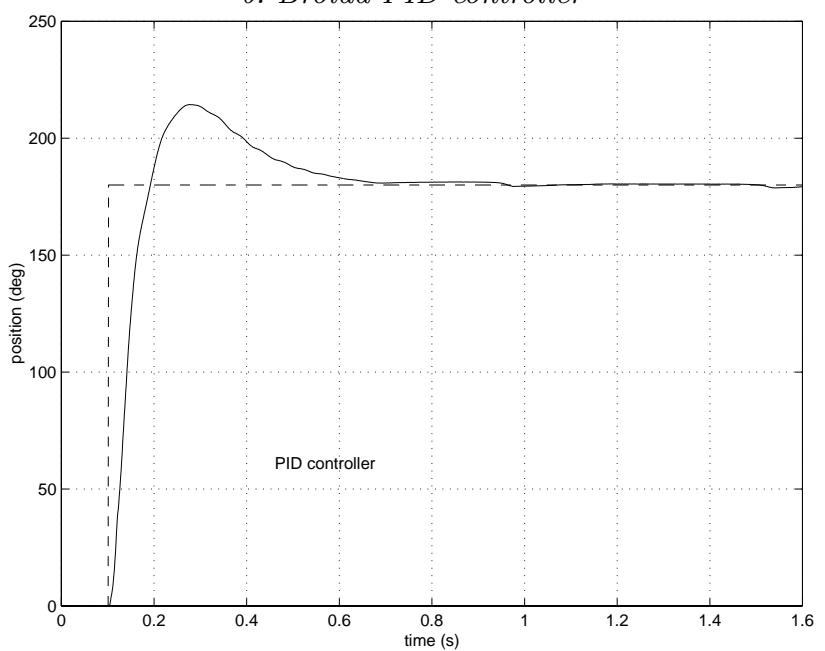

Fig. 6. Experimental results for the position control of the PMSM during step input. 
pre-defined optimized settings for the FLC parameters. These settings only depend on two or three parameters ( $K, T$ and eventually $\tau$ ) coming from an open-loop identification of the process. Experimental results show that it is now possible, as with the Broïda or Ziegler-Nichols methodologies for conventional PID controllers, to obtain satisfying results for FLC in just one open-loop identification test. In this way, these settings could be seen as an on-site efficient FLC tuning strategy.

It's however possible to notice the parameters settings sensitivity to system parameters variations or white noise has not been taken into account in the design procedure. Consequently, these settings should only be used in noiselessly environments or with systems where the open-loop identification has been done with a high precision degree. In this part, a second set of pre-established settings for the same PID-like FLC, that integrate, from the beginning of the design procedure, the robustness of the FLC, will be proposed. This new set can also be seen as a complement of the existing set. It will warrant a high performances process response on the considered benchmark combined with an high robustness. The process performances are always evaluated considering the integrative absolute error (IAE) between the reference and the measured signal. The FLC will then be all the more robust since this $I A E$-criterion remains insensitive to uncontrollable factors (here white noise, process misindentification or high order process). To some extent, it is thus possible to say that we want to provide settings for the PID-like FLC that satisfy a multiobjective criterion: on the one hand, the $I A E$-criterion, on the other hand the robustness (or the quality...) of the set of settings.

\subsection{Taguchi quality design of experiments}

Taguchi methods [10] were developed in Japan by Genichi Taguchi to improve the implementation of total quality control in Japan. They are based on the design of experiments to provide near optimal quality characteristics for a specific objective. The real power of Taguchi methods comes from their simplicity of implementation. The goal is not just to optimize an arbitrary objective function, but also to reduce the sensitivity of engineering designs to uncontrollable factors or noise. Taguchi methods are also called robust design in the USA.

In the traditional experimentation strategy, one supposes that the factors on which we act, are perfectly controlled and that their values remain constant throughout all experiment. The factors not included in the study are supposed not to vary. This concept is however well too theoretical because no one is certain that these factors remain constant indeed. To avoid the bias caused by these uncontrollable factors, the traditional experimental strategy consists in making the experiments in a random order. The effects of uncontrollable factors are then included in the experimental results dispersion. One thus seeks to eliminate all the possible variation sources, which is unfortunately often impossible in practice.

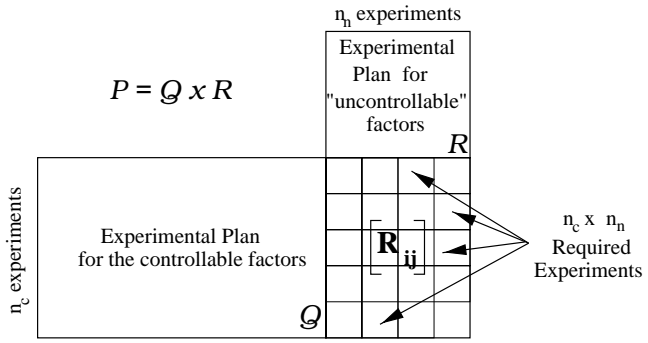

Fig. 7. Experimental product-plan.

Taguchi, on the other hand, considers that rather than to eliminate the causes from the variations, it is preferable to analyze them and to find experimental conditions for which these causes have a minimum effect. Thus, instead of seeking to eliminate the variation causes (called noises by Taguchi), he proposes to minimize their influence. The factors are divided into two categories: the factors relating to the system on which one can easily act (called controllable factors) and the factors (called noise factors) whose possible variations are not (or are with difficulty) controllable and can generate a degradation of the system characteristics. For the study of the controllable factors effects and for the determination of optimum settings for these factors in as few experiments as possible, one can refer to the experimental designs strategy presented in the last paragraph. Taking into account the noise factors in this strategy is however far from being obvious. Therefore Taguchi proposes a strategy based on two cross experimental designs (called product-plans): a first experimental design $(\mathcal{Q})$ for the controlled factors, a second experimental design $(\mathcal{R})$ for the noise factors (Fig. 7).

At each combination of the controlled factors is associated an experimental design for the noise factors. There is thus on the whole $\left(n_{\mathrm{c}} \times n_{\mathrm{n}}\right)$ different experiments. Thanks to the experimental product-plan $\mathcal{P}$, it will be possible to determine the best combination of the controllable factors in order to obtain the desired characteristics with a minimal variability. Of course, the counterpart of this robustness concept is a much higher number of required experiments.

Starting from the experimental product-plan, the aim is yet to obtain experimental informations representing at the same time the studied characteristics and the variability of these characteristics. The Taguchi approach is empirical and proposes, for solving this problem, a set of functions called signal-to-noise functions. These functions are used to measure the effect of the noise factors on the performance characteristics. In order to find at the same time the best experimental conditions making it possible to obtain optimal performances and minimal sensitivity to noise factors, Taguchi proposes to maximize the function signal-to-noise defined by (10).

$$
\forall i \in\left\{1, \ldots, n_{\mathrm{c}}\right\}, \quad(S / N)_{i}=-10 \log \left(\frac{\sum_{j=1}^{n_{\mathrm{n}}} R_{i j}^{2}}{n_{\mathrm{c}}}\right) .
$$


Table 4. Levels 1 and 2 for the noise factors.

\begin{tabular}{ccc}
\hline Factors & Level 1 & Level 2 \\
\hline$N_{1}$ & $\sigma_{W N}^{2}=0$ & $\sigma_{W N}^{2}=0.004$ \\
$N_{2}$ & 2nd order & 3rd order \\
$N_{3}$ & perfect & $\tau+15 \%, T+26 \%$ \\
\hline
\end{tabular}

This function depends however only on the various results $R_{i j}$ without taking into account the dispersion of them around their average value. Thus, many statisticians think that it is preferable to use two different functions, a first one which measures the performance characteristic, a second one devoted to the measure of this characteristic variability. In our case, it seems more judicious (and it is the solution that we will retain) to use $\overline{R_{i}}(11)$ and $-\log \left(s_{i}^{2}\right)(12)$ rather than the function $(S / N)_{i}$ to qualify on one hand the performance of an FLC adjustment and on the other hand its robustness with respect to the noise factors.

$$
\begin{gathered}
\forall i \in\left\{1, \ldots, n_{\mathrm{c}}\right\}, \overline{R_{i}}=\sum_{j=1}^{n_{\mathrm{n}}} \frac{R_{i j}}{n_{\mathrm{n}}} \\
\forall i \in\left\{1, \ldots, n_{\mathrm{c}}\right\},-\log \left(s_{i}^{2}\right)=-\log \left(\sum_{j=1}^{n_{\mathrm{n}}} \frac{\left(R_{i j}-\overline{R_{i}}\right)^{2}}{n_{\mathrm{n}}-1}\right) .
\end{gathered}
$$

\subsection{Application on the PID-like FLC}

The nine tuning parameters are the same as before. The two levels chosen for each of these factors are provided in Table 1, they are chosen in the same way as in the last part too. In our case, simulations have been done considering $K=5, T=0.192 \mathrm{~s}$ and $\tau=2 \mathrm{~s}$ and by taking into account three types of noise factors. The first one, called $N_{1}$, consists in the presence of an additional white noise on the measured signal (variance $\sigma_{W N}^{2}=0.004$ ). The second one, called $N_{2}$, refers to the order of the considered system (two different order systems leading to the same openloop identification have been considered). The last one, called $N_{3}$, is intended to evaluate the effect of an openloop process misidentification on the robustness. All the chosen levels for these three noise factors are presented in Table 4.

The nine controllable factors have been studied considering a $\mathrm{L}_{16}\left(2^{15}\right)$-Taguchi table $[6,11]$ and the three noise factors considering a $\mathrm{L}_{4}\left(2^{3}\right)$-Taguchi table. In our case, the measured result $R_{i j}$ is the $I A E$-criterion. The simulations results are provided in Table 5 .

According to this table, it is possible to determine the effect of each controllable factor on the $\overline{I A E}$-criterion and on the robustness [11]. The obtained results are given in Table 6.

Thanks to Table 6 , it is possible to determine the combination of controllable factors levels that optimize the $\overline{I A E}$-criterion with an as high robustness (measured through $\left.-\log \left(S^{2}\right)\right)$ as possible. The counterpart of the experimental designs methodology (and for the doing of only 64 experiments among 4096 possible experiments) is the necessity of making some approximations to determine this optimum combination. The first approximation that can be done applies the so-called inheritance rule. According to this rule, it is possible to underline in Table 6 the effect of controllable factors or first order interactions that may be prevailing on the $\overline{I A E}$-criterion. In the factors levels optimal combination determination process, the Taguchi methodology recommends to determine, in a first time, this optimum combination according to the only $\overline{I A E}$-criterion and then to modify if necessary this combination in order to take into account the robustness aspect.

Consequently, we first just consider the numerical values of the effects given by Table 6 on the $\overline{I A E}$-criterion. In a first time, the nine effects of controllable factors are used to determine a combination that should minimize the $\overline{I A E}$-criterion if there were no interactions: $A_{2} B_{2} C_{2} D_{2} E_{1} F_{1} G_{2} H_{1} I_{2}$. Six controllable factors ( $A, E$, $F, G, H$ and $I$ ) seam however to be most influencive. Considering the values of the first order interactions between these factors, it can be said that the level chosen for factor $C$ could be affected. Effect of factor $C$ appears indeed increased by effects of two non-negligible first order interactions.

Therefore, the real effect of factor $C$ on the $\overline{I A E}$ criterion may be masked and the optimized combination is also: $A_{2} B_{2} C_{1} D_{2} E_{1} F_{1} G_{2} H_{1} I_{2}$. A new simulation with these settings results in a $\overline{I A E}$-criterion equal to 0.566 , that improves, the best result obtained so far.

We now have to modify these settings in order to take into account the robustness aspect. Accordingly, we now consider the controllable factors effects on the $-\log \left(S^{2}\right)$ criterion. Factors $A, D, E, G, H$ and $I$ don't make any problem because their optimum levels according to the $-\log \left(S^{2}\right)$-criterion are the same as those chosen according to the $\overline{I A E}$-criterion. Factor $B$ is the most influent on the robustness and is less influent on the $\overline{I A E}$-criterion, so factor $B$ was modified. Effect of factor $C$ seams to be relatively important on the robustness. This effect appears however added with the effect of two important first order interactions, so factor $C$ real effect is also probably less important as it appears. Therefore, we don't envisaged any level modification for factor $C$. The case of factor $F$ is more difficult to solve. Factor $F$ effects on the two chosen criterion are moderate. The two settings level possibilities have thus been tested and the solution $F_{2}$ leads to the best compromise between performances and robustness. In conclusion, the combination $A_{2} B_{1} C_{1} D_{2} E_{1} F_{2} G_{2} H_{1} I_{2}$, which provides $\overline{I A E}=0.843$ and $-\log \left(S^{2}\right)=2.176$, is retained.

At this step and as in the determination procedure of the standard settings, a simplex optimization has been led on the major influencive factors, to ensure a fine optimization of the settings in the vicinity of those obtained above. The optimization criterion is here $\overline{I A E}$ but a close attention is also paid to robustness. The result of this simplex 
Table 5. Simulation results (product-plan).

\begin{tabular}{|c|c|c|c|c|c|c|c|c|c|c|c|c|c|c|c|}
\hline & & & & & & & & & \multicolumn{5}{|c|}{ Noise factors } & & \\
\hline & & & & & & & & & $z_{1}^{\infty}$ & - & N & $N$ & - & & \\
\hline & & & & & & & & & $z^{2}$ & - & N & - & $N$ & & \\
\hline & & & & & & & & & $z_{z}$ & - & $\dashv$ & $N$ & $N$ & & \\
\hline Exp. & $\mathrm{A}$ & B & $\mathrm{C}$ & $\mathrm{D}$ & $\mathrm{E}$ & $\mathrm{F}$ & G & $\mathrm{H}$ & I & $I A E_{1}$ & $I A E_{2}$ & $I A E_{3}$ & $I A E_{4}$ & $\overline{I A E}$ & $-\log \left(\boldsymbol{S}^{2}\right)$ \\
\hline 1 & 1 & 1 & 1 & 1 & 1 & 1 & 1 & 1 & 1 & 1.792 & 1.918 & 2.117 & 2.006 & 1.958 & 1.723 \\
\hline 2 & 1 & 1 & 2 & 2 & 1 & 1 & 2 & 2 & 2 & 0.868 & 0.901 & 1.009 & 0.924 & 0.926 & 2.440 \\
\hline 3 & 1 & 1 & 1 & 1 & 2 & 2 & 2 & 1 & 2 & 1.018 & 1.183 & 1.205 & 1.031 & 1.109 & 2.014 \\
\hline 4 & 1 & 1 & 2 & 2 & 2 & 2 & 1 & 2 & 1 & 2.602 & 2.898 & 2.439 & 2.225 & 2.541 & 1.094 \\
\hline 5 & 1 & 2 & 1 & 1 & 2 & 1 & 1 & 2 & 2 & 0.702 & 3.719 & 0.899 & 1.361 & 1.670 & -0.288 \\
\hline 6 & 1 & 2 & 2 & 2 & 2 & 1 & 2 & 1 & 1 & 1.384 & 1.466 & 2.254 & 1.347 & 1.613 & 0.732 \\
\hline 7 & 1 & 2 & 1 & 1 & 1 & 2 & 2 & 2 & 1 & 1.718 & 2.436 & 2.230 & 1.350 & 1.933 & 0.615 \\
\hline 8 & 1 & 2 & 2 & 2 & 1 & 2 & 1 & 1 & 2 & 1.336 & 1.294 & 1.024 & 0.945 & 1.150 & 1.423 \\
\hline 9 & 2 & 1 & 1 & 2 & 2 & 1 & 1 & 1 & 2 & 0.630 & 0.703 & 1.062 & 0.963 & 0.839 & 1.372 \\
\hline 10 & 2 & 1 & 2 & 1 & 2 & 1 & 2 & 2 & 1 & 1.183 & 1.610 & 1.533 & 1.153 & 1.369 & 1.256 \\
\hline 11 & 2 & 1 & 1 & 2 & 1 & 2 & 2 & 1 & 1 & 1.174 & 1.373 & 1.417 & 1.177 & 1.285 & 1.786 \\
\hline 12 & 2 & 1 & 2 & 1 & 1 & 2 & 1 & 2 & 2 & 1.249 & 1.606 & 1.027 & 0.955 & 1.209 & 1.068 \\
\hline 13 & 2 & 2 & 1 & 2 & 1 & 1 & 1 & 2 & 1 & 0.942 & 1.805 & 1.229 & 1.084 & 1.265 & 0.844 \\
\hline 14 & 2 & 2 & 2 & 1 & 1 & 1 & 2 & 1 & 2 & 0.447 & 0.569 & 0.683 & 0.621 & 0.580 & 1.998 \\
\hline 15 & 2 & 2 & 1 & 2 & 2 & 2 & 2 & 2 & 2 & 0.708 & 1.548 & 0.823 & 1.403 & 1.120 & 0.757 \\
\hline 16 & 2 & 2 & 2 & 1 & 2 & 2 & 1 & 1 & 1 & 1.617 & 1.721 & 1.605 & 1.283 & 1.556 & 1.444 \\
\hline
\end{tabular}

Table 6. Calculation of controllable factors effects.

\begin{tabular}{ccc}
\hline Considered effect & Effect on $\overline{I A E}$ & Effect on $-\log \left(S^{2}\right)$ \\
\hline$\frac{E_{A_{1}}}{E_{B_{1}}}+E_{C D}$ & +0.230 & -0.048 \\
$\underline{E_{C_{1}}}+\left(E_{A D}+E_{B H}+\underline{E_{F G}}+\underline{E_{E I}}\right)$ & +0.022 & +0.326 \\
$\frac{E_{D_{1}}}{E_{E_{1}}}+E_{A C}$ & +0.015 & -0.164 \\
$\frac{E_{F_{1}}}{E_{G_{1}}}+E_{C G}$ & +0.040 & -0.038 \\
$\frac{E_{H_{1}}}{2}+E_{B C}$ & -0.095 & +0.219 \\
$\underline{E_{I_{1}}}+E_{C E}$ & -0.105 & -0.008 \\
\hline$E_{A B}+E_{E F}+E_{D H}+E_{G I}$ & +0.141 & -0.183 \\
$E_{A F}+E_{B E}+E_{D G}+\underline{E_{H I}}$ & -0.121 & +0.294 \\
$E_{B F}+\underline{E_{A E}}+E_{D I}+E_{G H}$ & +0.307 & -0.081 \\
$\frac{E_{F I}}{E_{A H}}+E_{B D}+E_{E G}$ & -0.001 & +0.272 \\
$E_{B I}+\frac{E_{A G}}{E_{B G}}+E_{D F}+E_{E H}$ & -0.034 & -0.059 \\
$\underline{E_{A I}}+E_{D E}$ & +0.077 & +0.112 \\
\hline
\end{tabular}



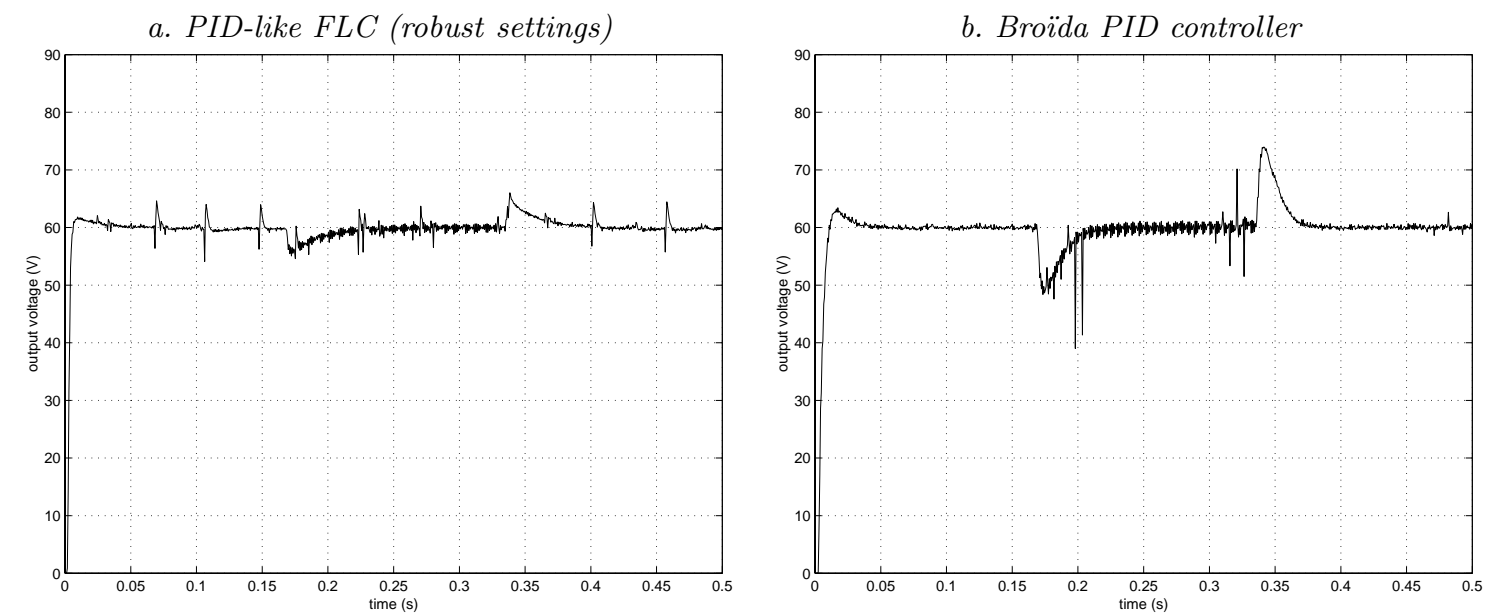

Fig. 8. Output voltage - DC/DC buck converter.

optimization is given in (13). These equations constitute a set of pre-established robust settings for a PID-like FLC and are devoted to non-evolutive open-loop stable systems [5].

$$
\left\{\begin{array}{l}
P S_{e}=0.28 \\
P V S_{e}=0.18 \\
P S_{d e}=0.70 \\
P V S_{d e}=0.21 \\
P S_{s}=0.80 \\
P V S_{s}=0.28 \\
K_{\mathrm{i}}=\frac{1.78}{K T} \\
e_{\mathrm{m}}=s_{\mathrm{m}} \\
d e_{\mathrm{m}}=\frac{1}{\tau T}(\tau+0.4 T) T_{\mathrm{samp}} s_{\mathrm{m}} \\
g_{\mathrm{m}}=\frac{2.26}{K T}(\tau+0.4 T) s_{\mathrm{m}} .
\end{array}\right.
$$

Now let us consider the case of evolutive open-loop systems. It is to be noted that robust settings for a PID-like FLC are obviously useless in so far as the integrator included in the loop yields a sufficient robust behavior of the system.

\subsection{Experimental results}

\subsubsection{DC/DC converter}

These pre-established robust settings (13) have to be tested on an experimental system. Therefore, we will first consider the same $1 \mathrm{~kW}$ DC/DC buck converter than before. Due to a relatively large-bandwidth low-pass filter $(500 \mathrm{~Hz})$, the PID-like FLC has to work in a noisy environment and the pre-established standard settings cannot be used. An open-loop identification test results in transfer function (14).

$$
F T_{\mathrm{Cv}}^{500 \mathrm{~Hz}}(s)=14.9 \frac{\mathrm{e}^{-0.0007 s}}{1+0.0099 s} .
$$

The experimental results obtained on this system and on the considered benchmark using our PID-like FLC with pre-established robust settings are provided in Figure $8 \mathrm{a}$. These results have to be compared because of a same adjustment methodology, with those obtained on the same benchmark and system using a conventional PID controller whose parameters have been set according to the Broïda settings (Fig. 8b).

The measured $I A E$-criterion is $0.542 \mathrm{Vs}$ in the FLC case and $0.786 \mathrm{Vs}$ in the classical PID case. Beyond this $30 \%$-criterion improvement, we can mainly underline the minimization of the nominal-load regulation impact on the output voltage.

\subsubsection{Permanent magnet synchronous motor}

The same test has been done on the speed regulation of the Mavilor BLS-112A permanent magnet synchronous motor (PMSM) already considered in Part 2. The low-pass filter on the speed measurement is here a $50 \mathrm{~Hz}$ first order filter. One open-loop identification test leads to transfer function (15).

$$
F T_{\mathrm{SM}}^{50 \mathrm{~Hz}}(s)=-1580 \frac{\mathrm{e}^{-0.010 s}}{1+0.206 s} .
$$

Experimental tests carried out on the PMSM, with a speed reference $N_{\text {ref }}=2000 \mathrm{rpm}$ and a torque pulse of $T=$ $4 \mathrm{Nm}$, considering the designed PID-like FLC with the pre-defined robust settings, lead to the results shown in Figure 9a. It is possible to measure an $I A E$-criterion equal to $33.4 \mathrm{rad}$ for the FLC and equal to $59.6 \mathrm{rad}$ for the conventional PID. Thus, we improve this criterion about $44 \%$ and, what is more important, the speed perturbation in case of a nominal load impact is about $70 \%$ smaller.

The experimental results presented till now show that it is now possible, as with the Broïda methodology for conventional PID controllers, to obtain satisfying and robust results for FLC after just one open-loop identification test. If the system to control works in a non-noisy environment or if it's possible to filter the measured signal using a 

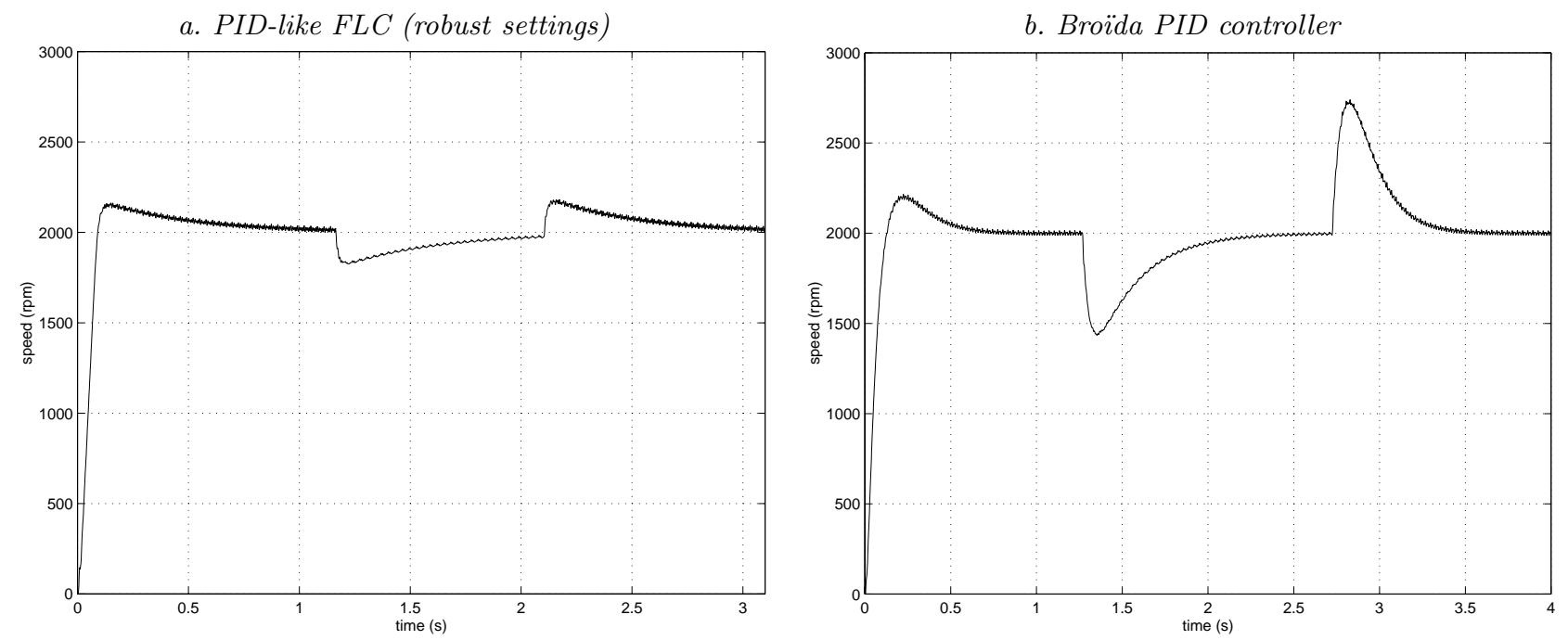

Fig. 9. Measured speed - PMSM.

very low-pass filter, the standard settings should be used. On the other hand, if noise factors (in Taguchi acception) may exist, the robust settings should be used to control the system.

The only remaining problem, considering the two different sets of pre-established settings provided before, resides in the fact that it's necessary to know (or to acquire...) the solicitation magnitude $s_{\mathrm{m}}$. For solving this problem, we propose, in the next part of this paper, a 3D-extension of the Taguchi quality design methodology.

\section{Solicitation magnitude}

\subsection{D-extension of Taguchi quality design}

In this part, the solicitation magnitude will be considered as another type of "uncontrollable factor", that comes in addition to those relative to the considered system (already described: white noise, process misidentification, order of the system). As we will see, this strategy will allow us to obtain two new criterions qualifying the robustness of the FLC versus the two types of uncontrollable factors. Therefore, we introduce the notion of three-dimensional product-plans (Fig. 10). The nine factors that define the FLC are located in the so-called $\mathcal{Q}$-table, the uncontrollable ones relating to the system in the $\mathcal{R}$-table and those relating to the magnitude of the solicitation in the $\mathcal{S}$-table. The combination of these three tables provides the experimental testing points (in our case simulations).

After having done the required simulations, the $\mathcal{Q}$ table is used to evaluate the effects of each factor on the $I A E$-criterion. As previously, the $\mathcal{R}$-table is used to evaluate the robustness of each factors level combination versus uncontrollable factors relating to the system. According to Taguchi, the chosen robustness criterion can here be defined by equation (16) (where $S_{R}$ is an estimation of the $I A E$-criterion standard deviation). Finally, the $\mathcal{S}$ table is used to evaluate the robustness of each factors le-

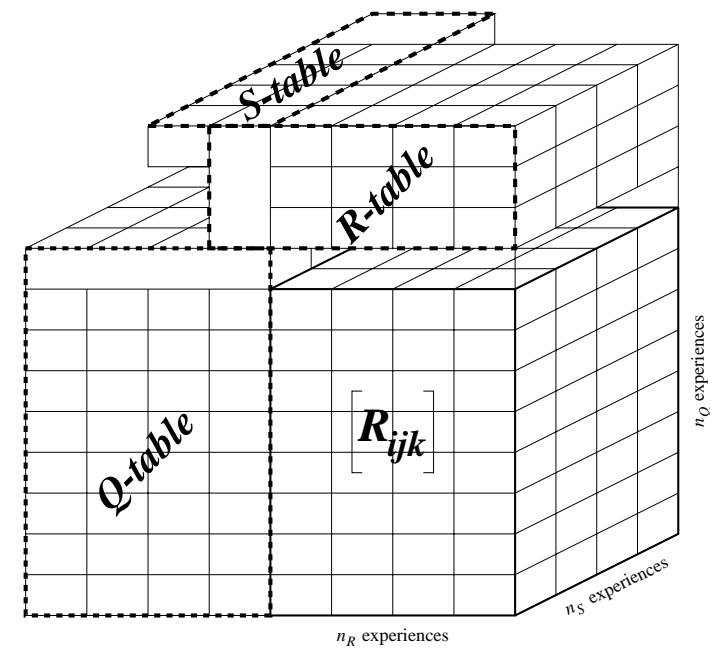

Fig. 10. 3D experimental product-plans.

vel combination versus solicitation magnitude (using criterion defined by Eq. (17)). The highest are the results of these two criteria, the highest is the robustness of the FLC. It is thus possible to determine a combination of factors levels which provides a good $I A E$-criterion with a high robustness.

$$
\begin{gathered}
\forall i \in\left\{1, \ldots, n_{Q}\right\}, \\
-\log \left(S_{R_{i}}^{2}\right)=-\log \left(\sum_{j=1}^{n_{R}} \frac{\left[\frac{1}{n_{S}} \sum_{k=1}^{n_{S}} R_{i j k}-\overline{R_{i}}\right]^{2}}{n_{R}-1}\right) \\
-\log \left(S_{S_{i}}^{2}\right)=-\log \left(\sum_{k=1}^{n_{S}} \frac{\left[\frac{1}{n_{R}} \sum_{j=1}^{n_{R}} R_{i j k}-\overline{R_{i}}\right]^{2}}{n_{S}-1}\right) .
\end{gathered}
$$


Table 7. Levels 1 and 2 for the magnitude noise factors.

\begin{tabular}{ccc}
\hline Factors & Level 1 & Level 2 \\
\hline$M_{1}$ & $s_{\text {nom }}+0$ & $s_{\text {nom }}+0.4 s_{\text {nom }}$ \\
$M_{2}$ & $s_{\text {nom }}+0$ & $s_{\text {nom }}-0.7 s_{\text {nom }}$ \\
\hline
\end{tabular}

\subsection{Application on the PID-like FLC}

The choice of factors levels for the tables $\mathcal{Q}$ and $\mathcal{R}$ is the same as in the last part of the paper. What is new here is that the normalization factor on input $e$ (called $e_{\mathrm{m}}$ ) is supposed to be determined considering the nominal value of the solicitation magnitude (called $s_{\text {nom }}$ ), rather than the real value of this solicitation $s_{\mathrm{m}}$. In order to obtain robust pre-established settings versus the solicitation magnitude, two noise factors, called $M_{1}$ and $M_{2}$ and dedicated to the evaluation of the system robustness versus this magnitude, have been introduced. Those represent respectively a positive or a negative solicitation magnitude variation from the standard level (Tab. 7).

In our case, the nine controllable factors have been studied considering a $\mathrm{L}_{16}\left(2^{15}\right)$-Taguchi table ( $\mathcal{Q}$-table in Fig. 10), the three noise factors relating to the system considering a $\mathrm{L}_{4}\left(2^{3}\right)$-Taguchi table ( $\mathcal{R}$-table in Fig. 10) and the two noise factors relating to the solicitation considering a $\mathrm{L}_{4}\left(2^{3}\right)$-Taguchi table ( $\mathcal{S}$-table in Fig. 10). The measured result $R_{i j k}$ is here the normalized $I A E$-criterion on the considered benchmark defined as follows:

$$
I A E=\frac{c_{n}}{c} \int_{0}^{t_{1}}|e(t)| \mathrm{d} t+\int_{t_{1}}^{t_{\max }}|e(t)| \mathrm{d} t .
$$

According to Taguchi quality design methodology, the determination of the effect of each controllable factor on the $I A E$-criterion and on the robustness (versus noises or solicitation magnitude) turns to be possible with a reduced number of simulations: 512 (only about $2 \%$ of the 16384 possible test points...). From this time onwards, it's easy to determine the best combination of controllable factors levels, which maximize the $I A E$-criterion with a robustness as high as possible.

After a fine optimization using the simplex algorithm, a last set of pre-established robust settings that integrates the robustness versus the solicitation magnitude can thus be obtained:

$$
\left\{\begin{array}{l}
P S_{e}=0.75 \\
P V S_{e}=0.26 \\
P S_{d e}=0.37 \\
P V S_{d e}=0.15 \\
P S_{s}=0.80 \\
P V S_{s}=0.60 \\
K_{\mathrm{i}}=\frac{1.50}{K T} \\
e_{\mathrm{m}}=s_{\mathrm{nom}} \\
d e_{\mathrm{m}}=\frac{2.55}{\tau T}(\tau+0.4 T) T_{\mathrm{samp}} s_{\mathrm{nom}} \\
g_{\mathrm{m}}=\frac{2.50}{K T}(\tau+0.4 T) s_{\mathrm{nom}} .
\end{array}\right.
$$

\subsection{Experimental results}

These settings have been tested on our two different experimental systems: the DC/DC buck converter and the permanent magnet synchronous motor (PMSM).

\subsubsection{DC/DC converter}

The pre-established robust settings, including versus solicitation magnitude, have been tested for three different solicitations values (40 V, $60 \mathrm{~V}, 80 \mathrm{~V}$ ) (Figs. 11a and 11b) and compared with the results obtained on the same benchmark with a conventional PID controller (Broïda settings - Fig. 11c). The measured voltage is still only filtered with a $500 \mathrm{~Hz}$ low-pass filter, leading to the same open-loop identification that in the last part of the paper (Eq. (14)).

As it can be seen on these provided experimental results, our pre-established robust settings for a PID-like fuzzy controller ensure much better performances as a conventional PID controller (tuned using the same very simple on-site methodology). Moreover, the behaviour depends no longer on the input magnitude. For memory, the measured $I A E$-criterion is $0.48 \mathrm{~V} \mathrm{~s}$ for the $\mathrm{FLC}(0.79 \mathrm{~V} \mathrm{~s}$ for the PID controller). Furthermore, a high level robustness (versus noises or magnitude of the solicitation (Fig. 11b)) of our PID-like controller is warranted thanks to the proposed 3D-adaptation of the Taguchi quality design approach.

\subsubsection{PMSM}

In a same way, these pre-established settings have been tested for the speed regulation of the PMSM and for three different solicitations (1500 rpm, $2000 \mathrm{rpm}, 2500 \mathrm{rpm}$ ) (Figs. 12a and 12b). Once again, the open-loop identification test is leading to the same transfer function that in the last part (Eq. (15)).

The obtained results have been compared with those obtained on the same benchmark and with the same onsite tuning methodology with a conventional PID controller (Fig. 12c). We can measure an $I A E$-criterion of $28.3 \mathrm{rad}$ for the proposed FLC and $59.6 \mathrm{rad}$ for the PID controller. Beyond this performances improvement, the robustness has also been highly improved.

\section{Field of validity}

As the field of validity of a tuning methodology should always be associated to its statement, Table 8 presents the limitations of the three types of proposed preestablished settings. These limitations have been obtained in an empirical way and constitutes the price to pay to guarantee a rather spectacular improvement of the dynamical performances. 


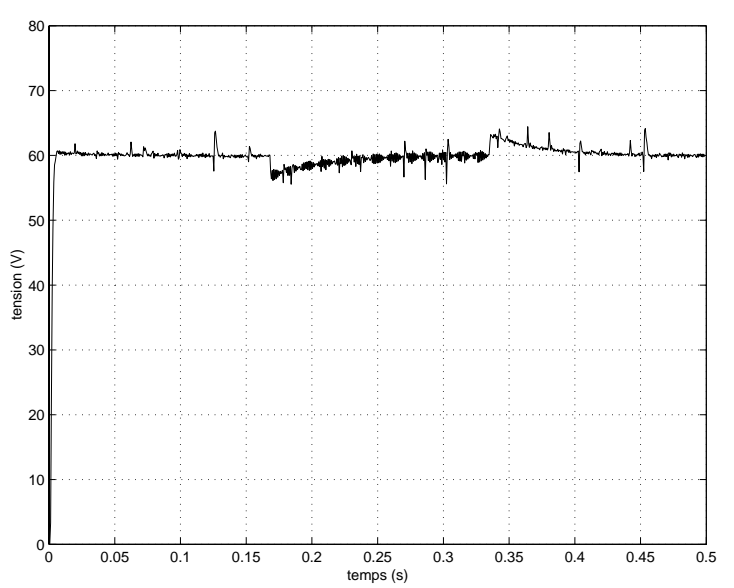

a. Proposed settings for the PID-like FLC.

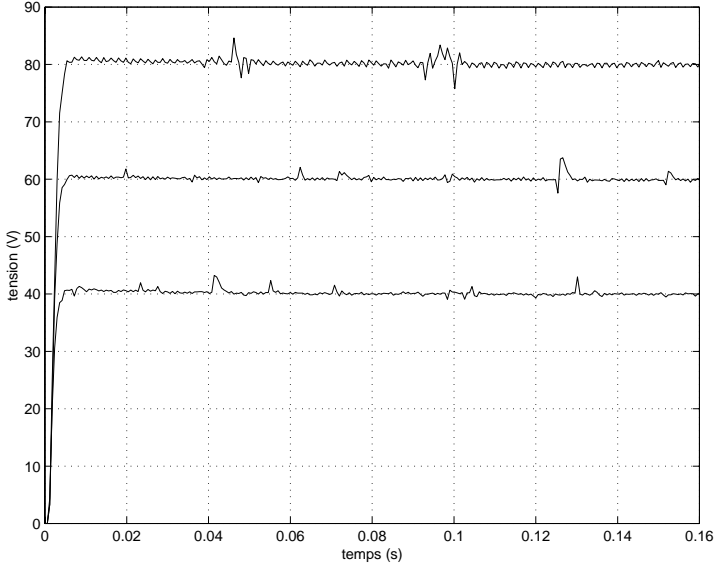

b. No-load step response (FLC)

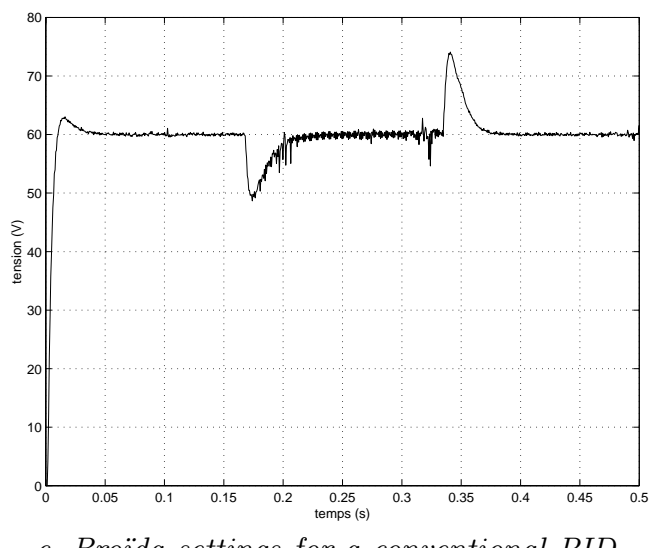

c. Broïda settings for a conventional PID.

Fig. 11. Experimental results on the DC/DC converter.

Table 8. Fields of validity of our preestablished settings.

\begin{tabular}{cccc}
\hline & $\begin{array}{c}\text { Standard settings } \\
(\text { Part 2) }\end{array}$ & $\begin{array}{c}\text { Robust settings } \\
(\text { Part 3) }\end{array}$ & $\begin{array}{c}\text { Solicitation magnitude } \\
\text { (Part 4) }\end{array}$ \\
\hline$T_{\text {samp }}$ & $\leq \frac{T}{20}$ & $\leq \frac{T}{7}$ & $\leq \frac{T}{8}$ \\
$\sigma_{W N}^{2}$ & $\leq 0.005$ & $\leq 0.013$ & $\leq 0.008$ \\
$\frac{T}{\tau}$ & $\leq 20 \%$ & $\leq 20 \%$ & $\leq 20 \%$ \\
Misidentification & up to 15\% & up to 70\% & up to $30 \%$ \\
& & (versus the real values of $(T, \tau)$
\end{tabular}

\section{Conclusion}

In this paper, we first briefly described the PID-like fuzzy logic controller that is used in the whole paper. Then, we propose a first set of pre-established settings for an open-loop stable or evolutive electrotechnical process. These settings are only based, as Ziegler-Nichols settings for conventional controllers, on a single open-loop identification test. They have been obtained thanks to the experimental designs methodology, from which some rudiments of knowledge are presented. A second set of pre-established settings is then proposed. It is a robust one, which integrates, from the design procedure and thanks to Taguchi quality design methodology, the robustness of the FLC in case of white noise, open-loop process misidentification or high order process. Nevertheless, this kind of robust settings suppose that the user knows (or can acquire) the solicitation magnitude. Therefore, a second set of robust settings that integrates, thanks to a 3D-extension of Taguchi quality design methodology, the robustness versus the solicitation magnitude is finally proposed. Experimental results in case of use with a DC/DC 


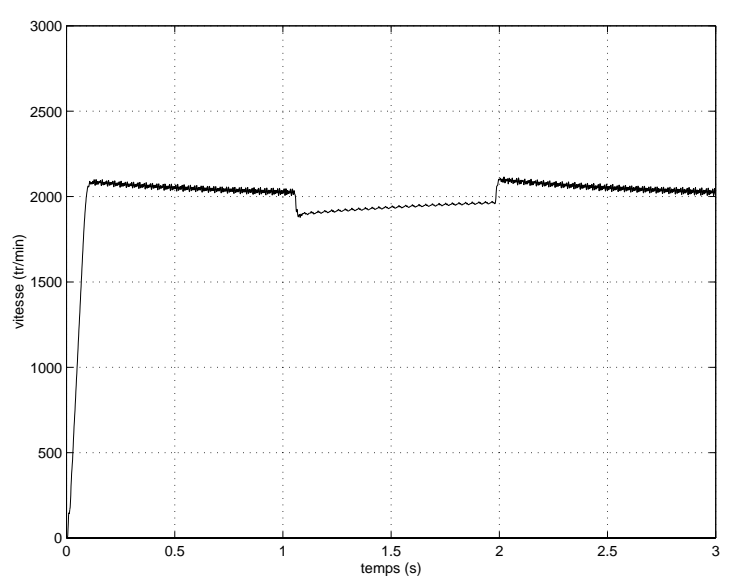

a. Proposed settings for the PID-like FLC.

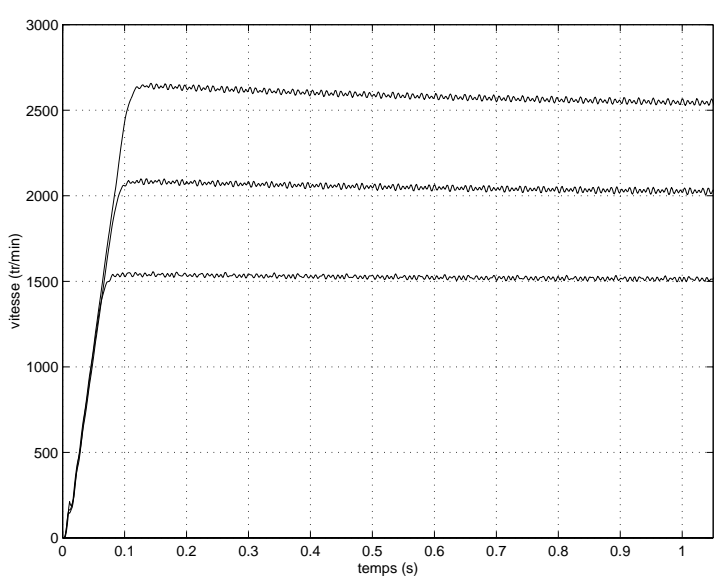

b. No-load step response (FLC)

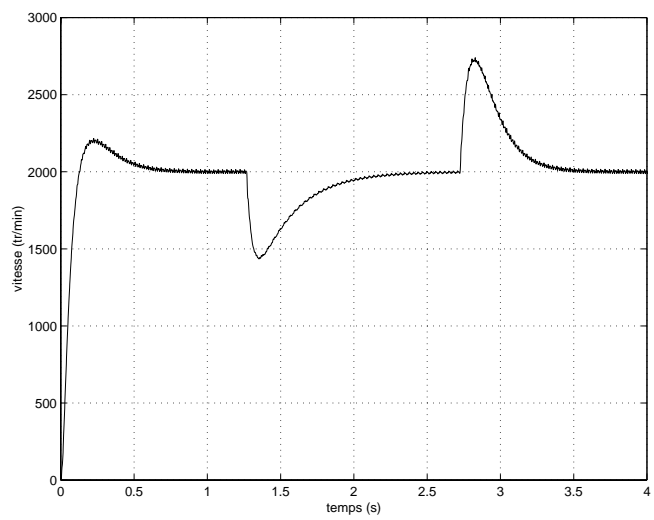

c. Broïda settings for a conventional PID.

Fig. 12. Experimental results on the PMSM.

converter or with a permanent magnet synchronous motor are presented for the three types of pre-defined settings.

In a more general way, it is possible to say that first of all came the PID-controller, easy to tune but with poor performances and a low robustness. Then came the Fuzzy Logic controller, which warranted a high dynamic and a sufficient robustness but which was very difficult to tune on-site by a non-specialist. In this paper, we concealed the advantages of these two types of controllers and their methods of adjustment to obtain fuzzy logic controllers as simple to tune on-site as a traditional PID. Of course, some limitations already exist, but if those are too constraining, the proposed methodology based on experimental designs can be applied another time to obtain a new set of preestablished settings.

\section{References}

1. V. Broïda, Automatisme, Régulation automatique, Servomécanismes (Dunod, Paris, 1956).

2. S. Galichet, L. Foulloy, IEEE Trans. Fuzzy Syst. 3, 140 (1995).

3. J. Goupy, La méthode des plans d'expériences (Dunod, Paris, 1988).
4. D. Hissel, P. Maussion, G. Gateau, J. Faucher, Fuzzy Logic Control Optimization of Electrical Systems using Experimental Designs, in Proc. of the EPE'97 Conference, Trondheim, Norway, 1997, pp. 1.090-1.095.

5. D. Hissel, P. Maussion, J. Faucher, On Evaluating Robustness of Fuzzy Logic Controllers through Taguchi Methodology, in Proc. of the IECON'98 Conference, Aachen, Germany, 1998, Vol. 1, pp. 17-22.

6. P. Maussion, D. Hissel, Optimized Fuzzy Logic Controller Parameters for Open-Loop Stable or Evolutive Electromechanical Systems, in Proc. of the IECON'98 Conference, Aachen, Germany, 1998, Vol. 1, pp. 23-27.

7. R.K. Mudi, R.P. Nikhil, IEEE Trans. Fuzzy Syst. 7, 2 (1999).

8. M. Pillet, Introduction aux plans d'expériences par la méthodologie Taguchi (Les Editions d'Organisation, Paris, 1994).

9. M. Sugeno, Industrial applications of fuzzy control (Elsevier Science Pub. Co., 1985).

10. G. Taguchi, M.S. Phadke, Quality Engineering through Design Optimization, in Proc. of the IEEE Globecom Conference, Atlanta, USA, 1984, pp. 1106-1113.

11. M. Vigier, Pratique des plans d'expériences (Les Editions d'Organisation, Paris, 1991).

12. J.G. Ziegler, N.B. Nichols, Optimum Settings for Automatic Controllers, in Proc. of ASME Transactions, 1942, Vol. 64, pp. 759-768. 